\title{
ChemComm
}

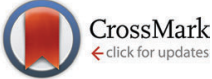

Cite this: Chem. Commun., 2015, 51, 11076

Received 10th April 2015, Accepted 28th May 2015

DOI: $10.1039 / \mathrm{c5cc02980e}$

www.rsc.org/chemcomm

\section{Rapid fabrication of highly b-oriented zeolite MFI thin films using ammonium salts as crystallization-mediating agents $\dagger$}

\author{
Xiaofei Lu, ${ }^{a}$ Yong Peng, ${ }^{a}$ Zhengbao Wang ${ }^{\star a}$ and Yushan Yan ${ }^{a b}$
}

\begin{abstract}
A new route to the synthesis of highly b-oriented zeolite MFI films is demonstrated for the first time using ammonium salts as crystallizationmediating agents in secondary growth. The ammonium salts tailor the crystallization process and silicate- $\mathrm{NH}_{4}{ }^{+}$interactions dominate over TPA- $\mathrm{NH}_{4}{ }^{+}$interactions so that nucleation was effectively suppressed during secondary growth.
\end{abstract}

Zeolites are crystalline materials which have a precisely defined pore structure, tunable composition and high stability. Zeolite thin films and layers have been widely synthesized and shown to have interesting properties as membranes and membrane reactors, ${ }^{1-3}$ chemical sensors, ${ }^{4}$ heat pumps, ${ }^{5}$ catalytic coating reactors ${ }^{6}$ and corrosion resistant coatings; ${ }^{7}$ thus there has been growing attention on the preparation of zeolite films in various fields. Due to the anisotropic pore structure of MFI zeolites, the orientation of constituent micro-crystals in a MFI zeolite membrane can significantly affect its molecular sieving effect and especially the highly b-oriented MFI films show superior separation performance. ${ }^{1,2,8-10}$

Thus far demonstrated synthesis approaches to b-oriented MFI films include secondary growth ${ }^{1,2,8-13}$ and in situ crystallization..$^{14,15}$ The advantage of the latter is its simplicity; however, some a-oriented MFI twin-crystals always exist, which affect molecular sieving properties and the roughness of the film. Moreover, b-oriented MFI films by in situ crystallization can only be obtained on some limited substrates, such as smooth metal, glass and silicon wafer surfaces. By taking advantage of the b-oriented seed layer, the secondary growth method has shown to be an effective method to prepare b-oriented MFI films and membranes. But it still requires the suppression of the growth of twin crystals. Since the growth of a-oriented twin crystals is generally believed to be unavoidable

\footnotetext{
${ }^{a}$ College of Chemical and Biological Engineering, and MOE Engineering Research Center of Membrane and Water Treatment Technology, Zhejiang University, Hangzhou 310027, P. R. China. E-mail: zbwang@zju.edu.cn;

Fax: +86-571-8795-2391; Tel: +86-571-8795-2391

${ }^{b}$ Department of Chemical and Biomolecular Engineering, University of Delaware, Newark, DE 19716, USA

$\dagger$ Electronic supplementary information (ESI) available. See DOI: 10.1039/c5cc02980e
}

when tetrapropylammonium hydroxide (TPAOH) is used as a structure-directing agent (SDA), developing a new specifically designed crystal shape-modifying SDA to enhance relative growth rates along the $b$-axis is important. For instance, Tsapatsis et al. designed trimer-TPAOH as an SDA to obtain highly b-oriented MFI membranes on mesoporous silica coated alumina supports. ${ }^{1}$ Yoon et al. used tetraethylammonium hydroxide (TEAOH) and $\left(\mathrm{NH}_{4}\right)_{2} \mathrm{SiF}_{6}$ as co-SDAs to prepare uniformly b-oriented MFI films by suppressing self-crystallization in the bulk medium of the secondary synthesis mixture. ${ }^{9}$ In their opinion, the method is highly economical, environmentally friendly and suitable for the production of uniformly oriented MFI films at an industrial scale. Recently, Zhou et al. reported the synthesis of highly b-oriented MFI zeolite films and membranes using the TPAOH/TEOS (tetraethoxysilane) $/ \mathrm{H}_{2} \mathrm{O} /$ HF system. ${ }^{10}$ However, trimer-TPAOH is difficult to synthesize and is expensive. Using TEAOH and $\left(\mathrm{NH}_{4}\right)_{2} \mathrm{SiF}_{6}$ as co-SDAs needs a long synthesis time (i.e., one week). With the use of fluoride ions $\left(\mathrm{F}^{-}\right)$as effective mineralizers and/or structure-directing molecules, the synthesis solution is severely corrosive, which limits the choice of substrate. Very recently, our group reported a new synthesis route to b-oriented MFI films under neutral conditions without the use of HF acid. ${ }^{11}$ However, the synthesis times are all longer than $24 \mathrm{~h}$ for the above-mentioned methods. Yang et al. obtained highly b-oriented MFI films by using TPAOH as the sole SDA during the secondary growth at $150{ }^{\circ} \mathrm{C}$ for $3 \mathrm{~h}$. They suppressed undesired twin growth on MFI films by hydrothermal pretreatment of the secondary synthesis solution before placing in the support. ${ }^{12}$ In a previous study, our group successfully suppressed undesired twin growth of MFI films by reducing the TPAOH amount in the secondary synthesis solution at $150{ }^{\circ} \mathrm{C}$ for $3 \mathrm{~h} .{ }^{13}$ However, it is still difficult to highly suppress twin growth by hydrothermal pretreatment or by reducing the TPAOH content. Therefore, further innovations are needed for a simple, economical and environmentally friendly scalable production of b-oriented MFI films and membranes.

Here we show a new route to the synthesis of highly b-oriented MFI films by using ammonium salts (e.g., $\left.\left(\mathrm{NH}_{4}\right)_{2} \mathrm{SO}_{4}\right)$ as crystallizationmediating agents. There are some reports showing that ammonium 
cations can greatly affect nucleation and crystal growth processes of zeolites and related materials. ${ }^{16,17}$ Nevertheless, the role of ammonium cations in the formation of zeolite films or membranes during the secondary growth has never been investigated. This is the first report demonstrating that twin growth of a b-oriented MFI seed layer using TPAOH as the SDA can be effectively suppressed by introducing ammonium salts as additives to the synthesis solution for secondary growth. In addition, a film formation mechanism is proposed and discussed in the context of general MFI nucleation and crystallization.

Several methods for the fabrication of high-quality b-oriented MFI seed monolayers have been developed, such as chemicalbonding induced assembly, ${ }^{18}$ manual assembly, ${ }^{19}$ air-water interfacial assembly, ${ }^{20,21}$ and the Langmuir-Blodgett technique. ${ }^{22}$ Among these methods, the manual assembly process is relatively simple and quick. Therefore, we fabricated highly b-oriented MFI seed monolayers on stainless steel plates by manually rubbing seed crystals, which has been pioneered by Yoon et al. ${ }^{19}$ Clearly, a close-packed and uniformly b-oriented MFI seed ( $1 \mu \mathrm{m}$ long) monolayer is obtained by rubbing (Fig. 1a). The secondary growth was carried out at $150{ }^{\circ} \mathrm{C}$ for $4 \mathrm{~h}$ and the detailed procedures are shown in the Experimental section ( $\mathrm{ESI} \dagger$ ).

The amount of $\left(\mathrm{NH}_{4}\right)_{2} \mathrm{SO}_{4}$ plays an important role in suppressing undesired twin growth in the secondary growth. The composition of synthesis solution for secondary growth is 1TEOS:0.2TPAOH: $200 \mathrm{H}_{2} \mathrm{O}: x\left(\mathrm{NH}_{4}\right)_{2} \mathrm{SO}_{4}$, and $x$ was varied from 0 to 0.1 . Undesired twin crystals are observed when the value of $x$ is lower than 0.05 (Fig. 1b-d). Using a synthesis solution containing no $\left(\mathrm{NH}_{4}\right)_{2} \mathrm{SO}_{4}$ during the secondary growth, substantial a-oriented twin crystals or a second layer was formed
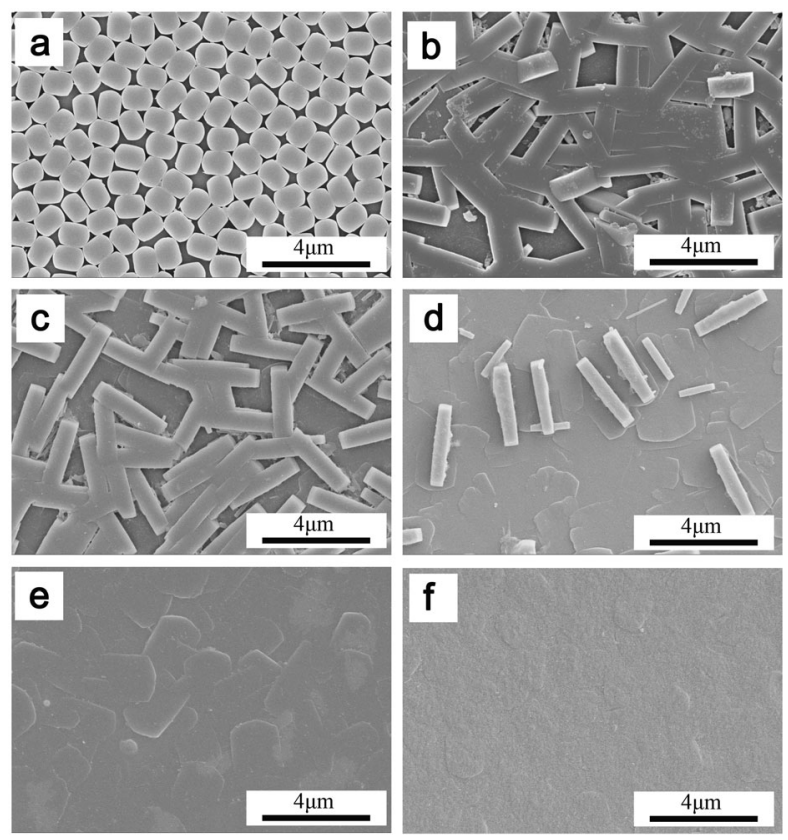

Fig. 1 SEM images of (a) MFI seed layer and ( $b-f)$ MFI films synthesized by secondary growth at $150{ }^{\circ} \mathrm{C}$ for $4 \mathrm{~h}$ in synthesis solutions with the molar composition of 1TEOS:0.2TPAOH: $200 \mathrm{H}_{2} \mathrm{O}: x\left(\mathrm{NH}_{4}\right)_{2} \mathrm{SO}_{4}, x=$ (b) 0 , (c) 0.025 , (d) 0.05 , (e) 0.075 and (f) 0.1 . before the complete filling up of the intercrystalline gaps between the seed crystals (Fig. 1b). When the value of $x$ is higher than 0.075 (including 0.075) (Fig. 1e and f), a smooth and continuous b-oriented MFI film was observed, and barely any a-oriented twin crystals existed. The thickness of the film is $\sim 0.46 \mu \mathrm{m}$ at $x=0.1$ (Fig. S1, ESI $\dagger$ ).

Corresponding XRD patterns of a seed layer and MFI films are shown in Fig. 2. Only five distinct peaks at 8.828, 17.748, 26.788, 36.008 , and 45.488 attributed to (020), (040), (060), (080), and (0100) reflections are observed for $x \geq 0.075$, indicating that the film is indeed perfectly b-oriented. When the value of $x$ is $\leq 0.05$, four shoulder peaks observed at 17.618, 26.588, 35.728, and 45.108 are attributed to (400), (600), (800) and (1000) reflections, indicating the existence of twin crystals. These results are consistent with the SEM observations. In brief, undesired twin growth of the MFI seed layer has been effectively inhibited with the help of $\left(\mathrm{NH}_{4}\right)_{2} \mathrm{SO}_{4}$ in the secondary growth.

To find out whether different ammonium salts have the same role as $\left(\mathrm{NH}_{4}\right)_{2} \mathrm{SO}_{4}, \mathrm{NH}_{4} \mathrm{HCO}_{3}$ was chosen as an additive. The effect of the $\mathrm{NH}_{4} \mathrm{HCO}_{3} / \mathrm{SiO}_{2}$ ratio was also investigated. Highly b-oriented MFI films (without twin crystals) were also obtained when the $\mathrm{NH}_{4} \mathrm{HCO}_{3} / \mathrm{SiO}_{2}$ ratio was 0.15 (Fig. S2, $\mathrm{ESI} \dagger$ ), which is similar to the case of $\left(\mathrm{NH}_{4}\right)_{2} \mathrm{SO}_{4}$.

Effects of the synthesis time on the compactness and twin growth of b-oriented MFI films synthesized in the synthesis solution with a

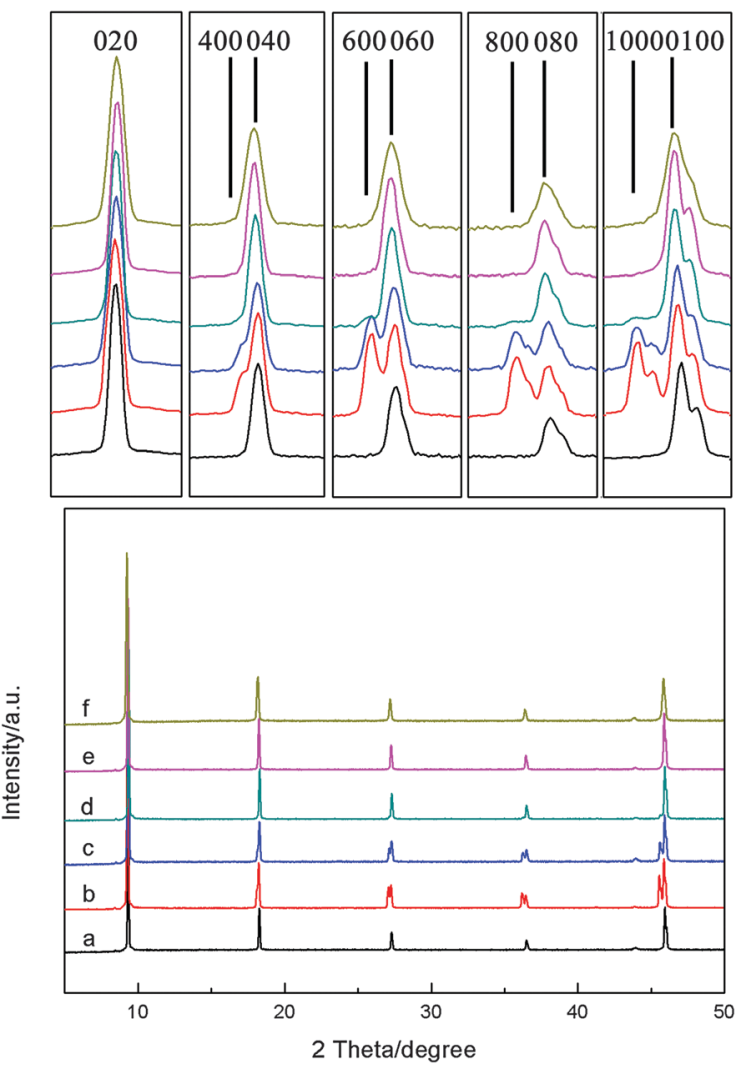

Fig. 2 XRD patterns of as-prepared (a) MFI seed layer and (b-f) films after the secondary growth at $150{ }^{\circ} \mathrm{C}$ for $4 \mathrm{~h}$ in the synthesis solution 1TEOS:0.2TPAOH:200H $\mathrm{H}_{2} \mathrm{O}: x\left(\mathrm{NH}_{4}\right)_{2} \mathrm{SO}_{4}, x=$ (b) 0 , (c) 0.025 , (d) 0.05 , (e) 0.075 and (f) 0.1 . 
composition of 1TEOS:0.2TPAOH:200H $\mathrm{H}_{2} \mathrm{O}: 0.1\left(\mathrm{NH}_{4}\right)_{2} \mathrm{SO}_{4}$ were also investigated (Fig. S3, ESI $\dagger$ ). There were some holes on the films after the synthesis for $2 \mathrm{~h}$, while almost continuous MFI films could be obtained at $3 \mathrm{~h}$. The film was completely continuous after the synthesis for $4 \mathrm{~h}$ and almost no twin crystals were observed even after the synthesis for $12 \mathrm{~h}$. This indicates that ammonium salts can effectively suppress the twin growth during the secondary growth of b-oriented seed layers.

To understand the role of ammonium salts during the secondary growth, the crystallization of the synthesis solution with bare stainless steel plates was investigated. There were many MFI crystals on the surface of the bare stainless steel plate (mainly b-oriented) and in the bulk solution when no $\left(\mathrm{NH}_{4}\right)_{2} \mathrm{SO}_{4}$ was added to the synthesis solution. The amount of MFI crystals on the surface of the bare stainless steel plate (b-oriented) and in the bulk solution decreased upon increasing the amount of $\left(\mathrm{NH}_{4}\right)_{2} \mathrm{SO}_{4}$ (Fig. S4 and S5, $\mathrm{ESI} \dagger$ ). When the value of $x$ was 0.075 , there were few crystals formed on the surface of the bare stainless steel plate, whereas no crystals but some gel particles were yielded in the bulk solution. When the value of $x$ was 0.1 , there were no crystals formed on the surface of the bare stainless steel plate, and no crystals but many gel particles were yielded in the mother liquor. All these results indicate that the addition of ammonium salts can slow down the nucleation rate.

Fan et al. reported a new route to the synthesis of TS-1 using $\left(\mathrm{NH}_{4}\right)_{2} \mathrm{CO}_{3}$ as a crystallization-mediating agent. They showed that the presence of $\left(\mathrm{NH}_{4}\right)_{2} \mathrm{CO}_{3}$ not only drastically lowered the $\mathrm{pH}$ value, slowing down the crystallization process and leading to the uniform incorporation of Ti into the framework, but also modified the crystallization mechanism in the formation of TS- $1 .{ }^{17}$

As shown in Table $\mathrm{S} 1$ (ESI $\dagger$ ), the $\mathrm{pH}$ value of the common secondary synthesis solution (without $\left.\left(\mathrm{NH}_{4}\right)_{2} \mathrm{SO}_{4}\right)$ was 10.9. In contrast, after the addition of $\left(\mathrm{NH}_{4}\right)_{2} \mathrm{SO}_{4}$, the $\mathrm{pH}$ value of the synthesis solution decreased to 10.6, 10.1, 9.7 and 9.4 with $x=0.025,0.0 .05$, and 0.075 and 0.1 , respectively. The same result was obtained for $\mathrm{NH}_{4} \mathrm{HCO}_{3}$ as an additive (Table S1, $\mathrm{ESI} \dagger$ ). $\mathrm{OH}^{-}$ has a strong gel mineralization effect, allowing the condensation of moderately stable silicic/silicate species. ${ }^{17}$ A low $\mathrm{pH}$ value prevents nucleation, and slows down the crystallization process. To clarify the effect of the $\mathrm{pH}$ value on the morphology of MFI films, we carried out experiments in which we kept the amount of TPAOH in the synthesis solution constant while changing the $\mathrm{pH}$ value by adding $\mathrm{H}_{2} \mathrm{SO}_{4}$ into the synthesis solution. The results show that the amount of the undesired twin crystals decreased upon lowering the $\mathrm{pH}$ value (Fig. S6, ESI $\dagger$ ), indicating that the $\mathrm{OH}^{-}$concentration is a key factor to suppress twin crystals. However, the result shows that a low $\mathrm{pH}$ value of 9.0 could not completely prevent nucleation. There were no twin crystals on the film surface even with the $\mathrm{pH}$ value as high as $\sim 9.7$ when ammonium salts were added to the synthesis solution. Therefore, $\mathrm{NH}_{4}^{+}$cations play a major role in suppressing the twin growth. Actually, when ammonia water was used to make up the decrease of the $\mathrm{pH}$ value caused by the addition of $\left(\mathrm{NH}_{4}\right)_{2} \mathrm{SO}_{4}$, no twin crystals were observed on the b-oriented MFI films synthesized in the synthesis solution with $\left(\mathrm{NH}_{4}\right)_{2} \mathrm{SO}_{4}$ and $\mathrm{NH}_{3} \cdot \mathrm{H}_{2} \mathrm{O}$ (Fig. S7, ESI $\dagger$ ), which has the same $\mathrm{pH}$ value as that of the solution of 1TEOS:0.2TPAOH:200H $\mathrm{H}_{2} \mathrm{O}$. This indicates that ammonium cations play the role of suppressing twin growth alone. It was reported earlier that the addition of a small amount of ammonium cations in the synthesis mixture has an inhibiting effect significantly on the nucleation of ZSM-5 phases. ${ }^{16}$ The first step in the nucleation process consists of an interaction between the negatively charged species and the TPA ${ }^{+}$ ions. As ammonium ions are added, they compete for the anions and the number of silicate-TPA ${ }^{+}$complexes is reduced. Consequently, a smaller number of nuclei will be formed. In addition, the interaction of the structure-breaking ammonium cations with silicate species disorganizes the clathrated water structure of the silicates, leading to a slower silicate "precipitation" on the $\mathrm{TPA}^{+}$centers, where ordering (leading to the ZSM-5 structure) occurs. Consequently, the nuclei grow at a slow rate. Therefore, the presence of ammonium salts likely influences the nucleation process of MFI zeolites in two different ways: (1) addition of ammonium salts to the crystallization mixture significantly lowers the $\mathrm{pH}$ value of the synthesis solution; (2) $\mathrm{NH}_{4}^{+}$cations compete more for silicate with $\mathrm{TPA}^{+}$.

Taking into consideration zeolite nucleation and crystal growth in the bulk synthesis with ammonium salts ${ }^{16,17}$ and our current results, a b-oriented MFI film formation mechanism is proposed as follows (Fig. 3). It is generally accepted that the adherence of new MFI nuclei in the bulk solution to the $(0 k 0)$ faces of the original MFI seeds was the main reason of a-oriented twin growth during secondary growth. ${ }^{23,24}$ The hydrophobic hydration sphere formed around TPA in aqueous solution is partially or completely replaced by silica when a sufficient amount of soluble silicate species is available. ${ }^{25}$ The formed organic-inorganic composite species could contribute to nucleation and then evolve to zeolite crystals through several intermediate states. ${ }^{25,26}$ For the secondary growth in the synthesis solution of $0.2 \mathrm{TPAOH}: 1 \mathrm{TEOS}: 200 \mathrm{H}_{2} \mathrm{O}$, a sufficient amount of organic-inorganic composite species is available. Some contribute to nucleation and the other is beneficial for the considerable in-plane growth. The nuclei and growing crystals may attach on the top of seed crystals. Considering the MFI crystal structure (i.e., pores in the $a$ - and $b$-directions but not $c$-direction), oriented attachment along the $a$-direction may be preferred, and thus a-oriented twin crystals are formed (case A). When $\mathrm{NH}_{4}{ }^{+}$is introduced, silicate- $\mathrm{NH}_{4}{ }^{+}$interactions dominate over silicate- $\mathrm{TPA}^{+}$ interactions. There are some free TPA molecules and silicate species

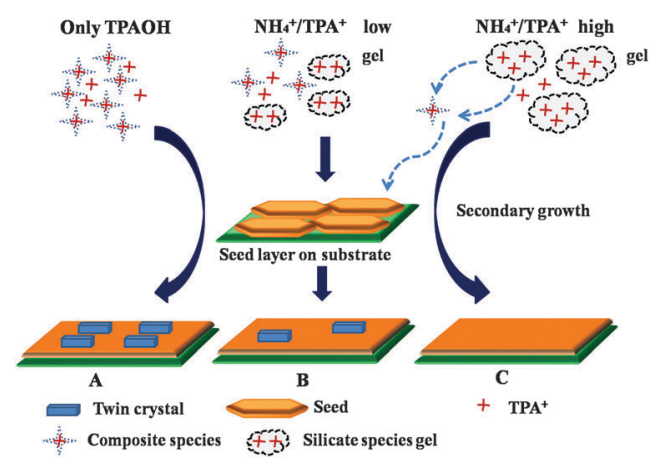

Fig. 3 Schematic representations of the secondary growth and twin crystal formation onto the seed layer for the synthesis solutions with various $\mathrm{NH}_{4}{ }^{+}$concentrations. 
at a low $\mathrm{NH}_{4}{ }^{+}$concentration, resulting in few twin crystals on the b-oriented MFI film (case B). When the value of $x$ is higher than 0.075 (e.g., 0.1), almost all the silicate species flocculate into a macromolecular colloid with the help of $\mathrm{NH}_{4}{ }^{+}$. With crystallization going on, the macromolecular colloid gradually dissociates into small pieces, which is the so-called secondary gel. Then the film grows at the expense of the continuous depletion of the amorphous material. The supplying nutrient is apt to crystal growth rather than nucleating. Therefore, there are no extra crystals produced on the bare substrate (Fig. S4, ESI $\dagger$ ) and only gel particles were yielded in the mother liquor, that is, there are almost no nuclei in the mother liquor and highly b-oriented MFI films without twin crystals can be obtained (case C). The observed crystal growth in the MFI films can be adequately explained by the above mechanism.

Chemical sensor and zeolite-modified electrode applications have been some of the major driving forces for the development of zeolite thin films. A zeolite film can improve the selectivity and sensitivity of the sensor due to its ability to selectively adsorb a component out of a mixture. To achieve selective adsorption and quick response, the zeolite film is required to be continuous (i.e., free of nonzeolitic pores) and thin, and have suitable orientation. Yan's group ${ }^{27}$ and Yang's group ${ }^{12}$ have proved the molecular sieving ability of the b-oriented MFI films using ions with different charges and sizes. To explore prospective applications, Yoon et al. ${ }^{9}$ incorporated hemicyanine dyes with varying chain lengths into uniformly b-oriented MFI films with a range of thicknesses and measured their nonlinear optical activities. This zeolite film can potentially be used as a matrix for investigating the optical and photophysical properties of a molecule in a controlled environment. The superior properties of b-oriented MFI membranes have been demonstrated in the separation of xylene isomers ${ }^{1,9}$ and $\mathrm{CO}_{2}-\mathrm{H}_{2}$ mixture ${ }^{10}$ in the literature. As shown in Fig. S8 (ESI $\dagger$ ), highly b-oriented MFI membranes can also be obtained on porous alumina supports in the synthesis solution with the addition of ammonium salts.

In summary, we have demonstrated that crystal orientation control in a continuous MFI thin film can be achieved by simple adjustment of the synthesis composition (TEOS/TPAOH/ $/ \mathrm{H}_{2} \mathrm{O}$ ) using ammonium salts (e.g., $\left.\left(\mathrm{NH}_{4}\right)_{2} \mathrm{SO}_{4}\right)$ as crystallization mediating agents in the secondary growth. The a-oriented twin crystals can be eliminated at the ratio of $\left(\mathrm{NH}_{4}\right)_{2} \mathrm{SO}_{4} / \mathrm{SiO}_{2}(x) \geq 0.075$. Different ammonium salts (e.g., $\mathrm{NH}_{4} \mathrm{HCO}_{3}$ ) have the similar effect in this process. Silicate- $\mathrm{NH}_{4}{ }^{+}$interactions dominated over silicate$\mathrm{TPA}^{+}$interactions so that nucleation was effectively suppressed. b-Oriented films on a silicon wafer and glass substrates can also be prepared by this process. There is no obvious corrosion of the silicon wafer and glass substrates. This simple synthesis method holds great potential for preparation of b-oriented zeolite films and membranes and therefore can open up doors in various fields.

This work is financially supported by the National Natural Science Foundation of China (21236006). Y.Y. thanks Zhejiang University for the Visiting Qiushi Scholar Professorship.

\section{Notes and references}

1 Z. P. Lai, G. Bonilla, I. Diaz, J. G. Nery, K. Sujaoti, M. A. Amat, E. Kokkoli, O. Terasaki, R. W. Thompson, M. Tsapatsis and D. G. Vlachos, Science, 2003, 300, 456.

2 J. Choi, H. K. Jeong, M. A. Snyder, J. A. Stoeger, R. I. Masel and M. Tsapatsis, Science, 2009, 325, 590.

3 S. Haag, M. Hanebuth, G. T. P. Mabande, A. Avhale, W. Schwieger and R. Dittmeyer, Microporous Mesoporous Mater., 2006, 96, 168.

4 Y. S. Yan and T. Bein, J. Am. Chem. Soc., 1995, 117, 9990.

5 M. Tatlier and A. Erdem-Senatalar, Microporous Mesoporous Mater., 2000, 34, 23.

6 M. L. Ji, G. Z. Liu, L. Wang and X. W. Zhang, AIChE J., 2014, 60, 1964.

7 Y. J. Dong, Y. Peng, Z. B. Wang and Y. S. Yan, Ind. Eng. Chem. Res., 2012, 51, 3646.

8 T. C. T Pham, T. H. Nguyen and K. B. Yoon, Angew. Chem., Int. Ed., 2013, 52, 8693.

9 T. C. T. Pham, H. S. Kim and K. B. Yoon, Science, 2011, 334, 1533.

10 M. Zhou, D. Korelskiy, P. C. Ye, M. Grahn and J. Hedlund, Angew. Chem., Int. Ed., 2014, 53, 3492.

11 Y. Peng, X. F. Lu, Z. B. Wang and Y. S. Yan, Angew. Chem., Int. Ed., 2015, 54, 5709.

12 Y. Liu, Y. S. Li and W. S. Yang, J. Am. Chem. Soc., 2010, 132, 1768.

13 X. M. Li, Y. Peng, Z. B. Wang and Y. S. Yan, CrystEngComm, 2011, 13, 3657.

14 Z. B. Wang and Y. S. Yan, Chem. Mater., 2001, 13, 1101.

15 Z. B. Wang and Y. S. Yan, Microporous Mesoporous Mater., 2001, 48, 229.

16 Z. Gabelica, N. Blom and E. G. Derouane, Appl. Catal., 1983, 5, 221.

17 W. B. Fan, R. G. Duan, T. Yokoi, P. Wu, Y. Kubota and T. Tatsumi, J. Am. Chem. Soc., 2008, 130, 10150.

18 K. Ha, Y. J. Lee, H. J. Lee and K. B. Yoon, Adv. Mater., 2000, 12, 1114; J. S. Lee, H. Lim, K. Ha, H. Cheong and K. B. Yoon, Angew. Chem., Int. Ed., 2006, 45, 5288.

19 J. S. Lee, J. H. Kim, Y. J. Lee, N. C. Jeong and K. B. Yoon, Angew. Chem., Int. Ed., 2007, 46, 3087.

20 Y. Liu, Y. S. Li and W. S. Yang, Chem. Commun., 2009, 1520.

21 M. Zhou and J. Hedlund, J. Mater. Chem., 2012, 22, 3307.

22 Z. Wang, T. Yu, P. Nian, Q. C. Zhang, J. K. Yao, S. Li, Z. N. Gao and X. L. Yue, Langmuir, 2014, 30, 4531.

23 D. G. Hay, H. Haeger and K. G. Wilshier, Zeolites, 1990, 10, 571.

24 A. Iwasaki, M. Hirata and I. Kudo, Zeolites, 1996, 16, 35.

25 S. L. Burkett and M. E. Davis, Chem. Mater., 1995, 7, 920.

26 S. Li, Z. J. Li, K. N. Bozhilov, Z. Chen and Y. S. Yan, J. Am. Chem. Soc., 2004, 126, 10732.

27 S. Li, X. Wang, D. Beving, Z. W. Chen and Y. S. Yan, J. Am. Chem. Soc., 2004, 126, 4122. 